Article

\title{
Different Role of Tumor Necrosis Factor-a Polymorphism in Non-Hodgkin Lymphomas among Caucasian and Asian Populations: A Meta-Analysis
}

Kan Zhai ${ }^{\dagger} *$, Jie Ding ${ }^{\dagger}$ and Yan Zhou

Medical Research Center, Beijing Chaoyang Hospital, Capital Medical University, Beijing 100020, China; E-Mails: ding201cy@sina.com (J.D.); abi373a@sohu.com (Y.Z.)

$\dagger$ These authors contributed equally to this work.

* Author to whom correspondence should be addressed; E-Mail: kan_zhai@sina.com; Tel./Fax: +86-10-8523-1624.

Received: 12 March 2014; in revised form: 15 April 2014 / Accepted: 23 April 2014 / Published: 5 May 2014

Abstract: Tumor necrosis factor- $\alpha$ (TNF- $\alpha)$ is an immunoregulatory cytokine involved in B- and T-cell function, and also plays an important role in inflammation and cancer. TNF- $\alpha-308 \mathrm{G}>\mathrm{A}$ has been associated with constitutively elevated TNF- $\alpha$ expression. Several studies have reported the association between the TNF- $\alpha-308 \mathrm{G}>\mathrm{A}$ polymorphism and non-Hodgkin lymphomas (NHL) risk, however, results are still inconsistent. To solve these conflicts, we conducted the first meta-analysis to assess the effect of TNF- $\alpha-308 \mathrm{G}>\mathrm{A}$ polymorphism on the risk of NHL and various subtypes (additive model) including 10,619 cases and 12,977 controls in Caucasian and Asian populations. Our meta-analysis indicated that TNF- $\alpha-308 \mathrm{G}>\mathrm{A}$ polymorphism is not associated with NHL risk when pooling all studies together $(\mathrm{OR}=1.06,95 \% \mathrm{CI}: 0.92-1.23, p=0.413)$. In stratified analyses, we found TNF- $\alpha-308 \mathrm{~A}$ allele was significantly associated with higher risk of NHL, B-cell lymphomas (BCL), T-cell lymphomas (TCL) and diffuse large B-cell lymphomas (DLBCL) in Caucasians (OR $=1.22,95 \% \mathrm{CI}: 1.06-1.40, p=0.007$; $\mathrm{OR}=1.18,95 \% \mathrm{CI}: 1.03-1.34, p=0.014 ; \mathrm{OR}=1.20,95 \% \mathrm{CI}: 1.01-1.42, p=0.040$; $\mathrm{OR}=1.21,95 \% \mathrm{CI}: 1.11-1.32, p<0.001$, respectively). Interestingly, it was associated with decreased risk of NHL, BCL and DLBCL in Asians (OR $=0.75,95 \%$ CI: 0.66-0.86, $p<0.001 ; \mathrm{OR}=0.70,95 \% \mathrm{CI}: 0.52-0.94, p=0.018$; OR $=0.70,95 \% \mathrm{CI}: 0.57-0.86$, $p=0.001)$. These findings also suggest TNF- $\alpha$ might play a distinct role in pathogenesis of NHL in different populations. 
Keywords: TNF- $\alpha$; polymorphism; NHL risk; meta-analysis; case-control

\section{Introduction}

Non-Hodgkin lymphomas (NHL), a complex group of heterogeneous diseases of uncontrolled B- or T-cell proliferation with distinct clinical and histological features, accounts for approximately $90 \%$ of all malignancy lymphomas [1]. Malignant transformation of B- or T-cells can occur at different stages of maturation, which reflects the heterogeneity of malignancies with various biologic and clinical behaviors. B-cell lymphomas (BCL) comprise $90 \%$ of NHL. Diffuse large B-cell lymphomas (DLBCL) and follicular lymphomas (FL) are the two major subtypes of BCL. Clinical outcome of NHL varies from subtype, diagnosis and response to treatment, however, prognosis of T-cell lymphoma (TCL) is usually worse than that of BCL. Etiology of NHL is still poorly understood, although epidemiological studies have shown that individuals with innate or acquired immune deficiencies, immunosuppression and infection are at increased risk of NHL [2,3]. Recently, accumulating evidence has suggested that genetic variations such as single nucleotide polymorphisms (SNPs) are associated with NHL risk and survival [4-9]. Moreover, previous studies showing a 2- to 3-fold risk of NHL with a family history of hematological malignancies indicates that genetic factors might play a critical role in NHL pathogenesis [10-12].

Tumor necrosis factor- $\alpha(\mathrm{TNF}-\alpha)$ is one of the most important pro-inflammatory and tumor-related cytokines for its regulating immune response, inflammation, Th1/Th2 balance and lymphomagenesis [13]. Increased serum values of TNF- $\alpha$ have been detected in autoimmune disease and many malignancies including lymphomas [14-17]. TNF- $\alpha-308 \mathrm{G}>\mathrm{A}$ (rs1800629) SNP has increased susceptibility to many kinds of tumors and autoimmune diseases, such as hepatocellular carcinoma, myeloma, lymphoma, ulcerative colitis, and Crohn's disease [18-20]. TNF- $\alpha-308$ A allele is associated with higher constitutive and inducible TNF- $\alpha$ expression by affecting a consensus binding site of a transcription factor named activator protein-2 (AP-2) [21,22]. Studies using knockout mouse have supported that this cytokine could affect progression of BCL directly or indirectly [23,24]. Although the TNF- $\alpha-308 \mathrm{G}>\mathrm{A}$ polymorphism has been widely assessed in association with NHL in different ethnicities, due to various sample sizes and genotyping methods, possibly because of NHL heterogeneity and other reasons, the results are still controversial.

In this study, we conducted the first comprehensive meta-analysis to test whether the TNF- $\alpha-308$ polymorphism is associated with NHL overall risk or its subtypes, especially BCL, TCL, DLBCL, FL, chronic lymphocytic leukemia/small lymphocytic lymphomas (CLL/SLL), mantel cell lymphomas (MCL), mucosal-associated lymphomas (MALT), peripheral T-cell lymphomas (PTCL) and natural killer/T-cell lymphomas (NK/TCL). We also performed subgroup analysis by descent (Caucasians and Asians) to assess a possible factor that might influence the overall results. Therefore, this study might have more statistical power and increase precision to estimate association between TNF- $\alpha-308$ polymorphism and its effect on NHL. 


\section{Results and Discussion}

\subsection{Eligible Studies}

In the initial screening for key words, 405 potential articles were identified in PubMed, Embase and Cochrane Library. After removing duplication, 321 articles were needed for further assessment. Among them, 293 were excluded because of inappropriate study design or control samples. Of the remaining 28 relevant articles, 8 articles were excluded for using the same patients. 2 articles were also excluded for their controls in concordance with Hardy-Weinberg equilibrium (HWE). With strict including criteria, the final pool of eligible articles consisted of 18 articles involving a total of 10,619 patients with NHL and 12,977 healthy controls. Because of the large sample size, Caucasians and Asians were considered as population stratification in this meta-analysis. Table 1 shows characteristics of eligible articles including ethnicity, genotyping method, number of cases and controls and NHL pathological types. In fact, at the primary data extraction, allele frequencies in all controls of one study, which performed by Skibola, did not fulfill HWE [25]. This study is a meta- and pooled analysis adding more genotyping data to the initial pooled report [26] to confirm the association between TNF/LTA polymorphism and NHL risk in Caucasian and Asian populations. For the new subjects (including Caucasians and Asians) not included in the initial report (all were Caucasians) [26], allele frequency of TNF- $\alpha-308 \mathrm{G}>\mathrm{A}$ in controls met HWE $(p=0.916)$. But TNF- $\alpha-308 \mathrm{G}>\mathrm{A}$ in all controls in the initial report was not consistent with HWE $(p=0.0007)$. We analyzed the initial report composed of 8 subgroups comprehensively [26]. Finally, we excluded data of EPILYMPH-Spain, University of California San Francisco and the NCI-SEER Seattle subgroup, in which controls did not fulfill HWE, and extracted data successfully. Since Skibola et al. [25] conducted this large pooled analysis in TNF polymorphism on NHL risk in Caucasians and Asians, we separated this paper into two studies according to population. In addition, 13 studies were conducted on Caucasians [16,27-38], and 4 were on Asians [39-42]. Several genotyping methods were used, including allelic specific polymerase chain reaction (ASPCR), polymerase chain reaction-restriction fragment length polymorphism (PCR-RFLP), polymerase chain reaction-solid-phase minisequencing (PCR-SPM), polymerase chain reaction-ligation detection reaction (PCR-LDR), TaqMan, Sequenom and sequencing.

Table 1. Characteristics of 18 eligible articles included in this meta-analysis.

\begin{tabular}{cccccc}
\hline \multirow{2}{*}{ Study } & Ethnicity & Genotyping Method & \multicolumn{2}{c}{ Samples } & Characteristics \\
\cline { 4 - 5 } & & NHLs (n) & Controls (n) & \\
\hline Chouchane, 1997 & Caucasians & ASPCR & 44 & 106 & All subtypes \\
Demeter, 1997 & Caucasians & PCR-RFLP & 63 & 117 & HCL only \\
Warzocha, 1998 & Caucasians & ASPCR & 273 & 96 & All subtypes \\
Fitzgibbon, 1999 & Caucasians & PCR-RFLP & 121 & 88 & FL only \\
Wihlborg, 1999 & Caucasians & PCR-SPM & 49 & 51 & CLL only \\
Mainou-Fowler, 2000 & Caucasians & PCR-RFLP & 76 & 40 & CLL \\
Juszczynski, 2002 & Caucasians & Sequencing & 204 & 120 & All subtypes \\
Hellmig, 2005 & Caucasians & TaqMan & 138 & 533 & MALT only \\
Bel Hadj Jrad, 2007 & Caucasians & PCR-RFLP & 194 & 160 & All subtypes \\
Jevtovic-Stoimenov, 2008 & Caucasians & PCR-RFLP & 80 & 34 & All subtypes \\
\hline
\end{tabular}


Table 1. Cont.

\begin{tabular}{cccccc}
\hline \multirow{2}{*}{ Study } & Ethnicity & Genotyping Method & \multicolumn{2}{c}{ Samples } & \multirow{2}{*}{ Characteristics } \\
\cline { 4 - 5 } & & NHLs (n) & Controls (n) & \\
\hline Fernberg, 2010 & Caucasians & Sequenom & 2267 & 1484 & All subtypes \\
Skibola, 2010 & Caucasians, Asians & TaqMan or Pyrosequencing & 4287 & 5591 & All subtypes \\
Xiao, 2011 & Asians & PCR-RFLP & 160 & 214 & All subtypes \\
Ibrahim, 2012 & Caucasians & PCR-RFLP & 84 & 100 & BCL only \\
Hosgood, 2013 & Asians & TaqMan & 291 & 300 & All subtypes \\
Lech-Maranda, 2013 & Caucasians & TaqMan & 288 & 192 & CLL only \\
Liu, 2013 & Asians & PCR-LDR & 1932 & 3622 & TCL only \\
Nasira, 2013 & Asians & PCR-RFLP & 68 & 129 & All subtypes \\
\hline
\end{tabular}

Abbreviations: NHL, non-Hodgkin lymphomas; ASPCR, allelic specific polymerase chain reaction; PCR-RFLP, polymerase chain reaction-restriction fragment length polymorphism; PCR-SPM, polymerase chain reaction-solid-phase minisequencing; PCR-LDR, polymerase chain reaction-ligation detection reaction; HCL, hairy cell leukemias; FL, follicular lymphomas; CLL, chronic lymphocytic leukemias; MALT, mucosal-associated lymphomas; BCL, B-cell lymphomas; TCL, T-cell lymphomas.

\subsection{Quantitative Synthesis}

Based on a large pooled sample size, we analyzed TNF- $\alpha-308 \mathrm{G}>\mathrm{A}$ polymorphism effects on risks of NHL, BCL, TCL and subtypes (DLBCL, FL, CLL/SLL, MCL, MALT, PTCL and NK/TCL) in additive model (A vs. G) which stratified by ethnicity (Caucasians and Asians). Results of meta-analysis and primary data extracted from studies are listed in Tables 2 and 3.

Table 2. Stratified analyses of TNF- $\alpha-308 \mathrm{G} / \mathrm{A}$ polymorphism on NHL risk in Caucasians and Asians *.

\begin{tabular}{|c|c|c|c|c|c|c|c|c|}
\hline \multirow{2}{*}{ Type } & \multirow{2}{*}{ Ethnicity } & \multirow{2}{*}{ Study (n) } & \multicolumn{2}{|c|}{ Samples } & \multirow{2}{*}{ OR $(95 \%$ CI $)$} & \multirow{2}{*}{$p$} & \multirow{2}{*}{$\mathbf{I}^{2}(\%)$} & \multirow{2}{*}{$p_{\text {het }}$} \\
\hline & & & Cases (n) & Controls (n) & & & & \\
\hline \multirow{3}{*}{ NHL } & Caucasians & 14 & 7893 & 8447 & $1.22(1.06-1.40)$ & 0.007 & 60.7 & 0.002 \\
\hline & Asians & 5 & 2726 & 4530 & $0.75(0.66-0.86)$ & $<0.001$ & 0.0 & 0.670 \\
\hline & Overall & 19 & 10,619 & 12,977 & $1.06(0.92-1.23)$ & 0.413 & 75.0 & $<0.001$ \\
\hline \multirow{3}{*}{$\mathrm{BCL}$} & Caucasians & 11 & 6369 & 8085 & $1.18(1.03-1.34)$ & 0.014 & 44.6 & 0.054 \\
\hline & Asians & 2 & 1723 & 3887 & $0.70(0.52-0.94)$ & 0.018 & 41.9 & 0.189 \\
\hline & Overall & 13 & 8092 & 11,972 & $1.07(0.91-1.26)$ & 0.411 & 74.4 & $<0.001$ \\
\hline \multirow{3}{*}{ TCL } & Caucasians & 2 & 467 & 6810 & $1.20(1.01-1.42)$ & 0.040 & 0.0 & 0.361 \\
\hline & Asians & 2 & 633 & 3922 & $0.96(0.74-1.23)$ & 0.723 & 57.8 & 0.124 \\
\hline & Overall & 4 & 1100 & 10,732 & $1.11(0.96-1.28)$ & 0.145 & 43.1 & 0.153 \\
\hline \multirow{3}{*}{ DLBCL } & Caucasians & 3 & 2325 & 6930 & $1.21(1.11-1.32)$ & $<0.001$ & 0.0 & 0.491 \\
\hline & Asians & 2 & 1028 & 3887 & $0.70(0.57-0.86)$ & 0.001 & 0.0 & 0.908 \\
\hline & Overall & 5 & 3353 & 10,817 & $0.97(0.75-1.26)$ & 0.840 & 83.9 & $<0.001$ \\
\hline \multirow{3}{*}{ FL } & Caucasians & 3 & 1233 & 6898 & $1.00(0.89-1.13)$ & 0.949 & 31.0 & 0.235 \\
\hline & Asians & 2 & 184 & 3887 & $0.72(0.47-1.12)$ & 0.142 & 12.4 & 0.285 \\
\hline & Overall & 5 & 1417 & 10,785 & $0.98(0.87-1.10)$ & 0.706 & 32.3 & 0.206 \\
\hline CLL/SLL & Caucasians & 6 & 1859 & 7127 & $1.02(0.92-1.13)$ & 0.767 & 13.8 & 0.326 \\
\hline MCL & Caucasians & 2 & 250 & 6810 & $1.25(1.00-1.57)$ & 0.052 & 0.0 & 0.560 \\
\hline MALT & Caucasians & 1 & 138 & 533 & $1.07(0.76-1.51)$ & 0.689 & & \\
\hline
\end{tabular}


Table 2. Cont.

\begin{tabular}{|c|c|c|c|c|c|c|c|c|}
\hline \multirow{2}{*}{ Type } & \multirow{2}{*}{ Ethnicity } & \multirow{2}{*}{ Study (n) } & \multicolumn{2}{|c|}{ Samples } & \multirow{2}{*}{ OR (95\% CI) } & \multirow{2}{*}{$p$} & \multirow{2}{*}{$I^{2}(\%)$} & \multirow{2}{*}{$p_{\text {het }}$} \\
\hline & & & Cases (n) & Controls (n) & & & & \\
\hline \multirow{3}{*}{ PTCL } & Caucasians & 1 & 183 & 5326 & $1.11(0.85-1.47)$ & 0.446 & & \\
\hline & Asians & 1 & 79 & 300 & $0.65(0.29-1.48)$ & 0.303 & & \\
\hline & Overall & 2 & 262 & 5636 & $1.05(0.80-1.36)$ & 0.741 & 32.9 & 0.222 \\
\hline NK/TCL & Asians & 2 & 190 & 3922 & $0.74(0.46-1.17)$ & 0.196 & 12.4 & 0.285 \\
\hline
\end{tabular}

* Fixed-effect model was used when $p$ value for heterogeneity test $>0.05$; otherwise, random-effect model was used; Abbreviations: TNF, tumor necrosis factor; NHL, non-Hodgkin lymphomas; BCL, B-cell lymphomas; TCL, T-cell lymphomas; DLBCL, diffuse large B-cell lymphomas; FL, follicular lymphomas; CLL/SLL, chronic lymphocytic leukemias/small lymphocytic lymphomas; MCL, mantel cell lymphomas; MALT, mucosal-associated lymphomas; PTCL, peripheral T-cell lymphomas; NK/TCL, natural killer/T-cell lymphomas.

Table 3. Summary of primary data from eligible studies in this meta-analysis.

\begin{tabular}{|c|c|c|c|c|c|c|c|c|}
\hline \multirow{2}{*}{ Type } & \multirow{2}{*}{ Ethnicity } & \multirow{2}{*}{ Study } & \multicolumn{3}{|c|}{ Cases } & \multicolumn{3}{|c|}{ Controls } \\
\hline & & & GG & GA & $\mathbf{A A}$ & GG & GA & $\mathbf{A A}$ \\
\hline \multirow{19}{*}{ NHL } & \multirow{14}{*}{ Caucasians } & Chouchane, 1997 & 11 & 33 & 0 & 72 & 33 & 1 \\
\hline & & Demeter, 1997 & 42 & 18 & 3 & 81 & 34 & 2 \\
\hline & & Warzocha, 1998 & 203 & 65 & 5 & 69 & 24 & 3 \\
\hline & & Fitzgibbon, 1999 & 96 & 23 & 2 & 64 & 22 & 2 \\
\hline & & Wihlborg, 1999 & 29 & 19 & 1 & 37 & 14 & 0 \\
\hline & & Mainou-Fowler, 2000 & 50 & 23 & 3 & 28 & 11 & 1 \\
\hline & & Juszczynski, 2002 & 151 & 49 & 4 & 85 & 32 & 3 \\
\hline & & Hellmig, 2005 & 93 & 39 & 6 & 360 & 160 & 13 \\
\hline & & Bel Hadj Jrad, 2007 & 120 & 59 & 15 & 107 & 49 & 4 \\
\hline & & Jevtovic-Stoimenov, 2008 & 32 & 46 & 2 & 19 & 14 & 1 \\
\hline & & Fernberg, 2010 & 1490 & 675 & 102 & 1007 & 431 & 46 \\
\hline & & Skibola, 2010 & 2712 & 1136 & 164 & 3791 & 1394 & 141 \\
\hline & & Ibrahim, 2012 & 41 & 21 & 22 & 67 & 27 & 6 \\
\hline & & Lech-Maranda, 2013 & 213 & 67 & 8 & 136 & 53 & 3 \\
\hline & \multirow{5}{*}{ Asians } & Skibola, 2010 & 243 & 29 & 3 & 212 & 49 & 4 \\
\hline & & Xiao, 2011 & 138 & 20 & 2 & 174 & 35 & 5 \\
\hline & & Hosgood, 2013 & 1702 & 221 & 9 & 3091 & 506 & 25 \\
\hline & & Liu, 2013 & 264 & 27 & 0 & 260 & 40 & 0 \\
\hline & & Nasira, 2013 & 58 & 9 & 1 & 105 & 22 & 2 \\
\hline \multirow{11}{*}{$\mathrm{BCL}$} & \multirow{11}{*}{ Caucasians } & Demeter, 1997 & 42 & 18 & 3 & 81 & 34 & 2 \\
\hline & & Fitzgibbon, 1999 & 96 & 23 & 2 & 64 & 22 & 2 \\
\hline & & Wihlborg, 1999 & 29 & 19 & 1 & 37 & 14 & 0 \\
\hline & & Mainou-Fowler, 2000 & 50 & 23 & 3 & 28 & 11 & 1 \\
\hline & & Juszczynski, 2002 & 72 & 29 & 3 & 85 & 32 & 3 \\
\hline & & Hellmig, 2005 & 93 & 39 & 6 & 360 & 160 & 13 \\
\hline & & Jevtovic-Stoimenov, 2008 & 24 & 29 & 2 & 19 & 14 & 1 \\
\hline & & Fernberg, 2010 & 1395 & 630 & 91 & 1007 & 431 & 46 \\
\hline & & Skibola, 2010 & 2221 & 915 & 139 & 3791 & 1394 & 141 \\
\hline & & Ibrahim, 2012 & 41 & 21 & 22 & 67 & 27 & 6 \\
\hline & & Lech-Maranda, 2013 & 213 & 67 & 8 & 136 & 53 & 3 \\
\hline
\end{tabular}


Table 3. Cont.

\begin{tabular}{|c|c|c|c|c|c|c|c|c|}
\hline \multirow{2}{*}{ Type } & \multirow{2}{*}{ Ethnicity } & \multirow{2}{*}{ Study } & \multicolumn{3}{|c|}{ Cases } & \multicolumn{3}{|c|}{ Controls } \\
\hline & & & GG & GA & $\overline{\mathbf{A A}}$ & GG & GA & $\overline{\mathbf{A A}}$ \\
\hline \multirow{2}{*}{$\mathrm{BCL}$} & \multirow{2}{*}{ Asians } & Skibola, 2010 & 194 & 23 & 2 & 212 & 49 & 4 \\
\hline & & Hosgood, 2013 & 1332 & 164 & 8 & 3091 & 506 & 25 \\
\hline \multirow{4}{*}{ TCL } & \multirow{2}{*}{ Caucasians } & Fernberg, 2010 & 95 & 45 & 11 & 1007 & 431 & 46 \\
\hline & & Skibola, 2010 & 216 & 90 & 10 & 3791 & 1394 & 141 \\
\hline & \multirow{2}{*}{ Asians } & Hosgood, 2013 & 287 & 54 & 1 & 3091 & 506 & 25 \\
\hline & & Liu, 2013 & 264 & 27 & 0 & 260 & 40 & 0 \\
\hline \multirow{5}{*}{ DLBCL } & \multirow{3}{*}{ Caucasians } & Fernberg, 2010 & 371 & 173 & 23 & 1007 & 431 & 46 \\
\hline & & Juszczynski, 2002 & 72 & 29 & 3 & 85 & 32 & 3 \\
\hline & & Skibola, 2010 & 1093 & 495 & 66 & 3791 & 1394 & 141 \\
\hline & \multirow{2}{*}{ Asians } & Skibola, 2010 & 86 & 11 & 2 & 212 & 49 & 4 \\
\hline & & Hosgood, 2013 & 829 & 97 & 3 & 3091 & 506 & 25 \\
\hline \multirow{5}{*}{ FL } & \multirow{3}{*}{ Caucasians } & Fitzgibbon, 1999 & 96 & 23 & 2 & 64 & 22 & 2 \\
\hline & & Fernberg, 2010 & 297 & 115 & 12 & 1007 & 431 & 46 \\
\hline & & Skibola, 2010 & 489 & 167 & 32 & 3791 & 1394 & 141 \\
\hline & \multirow{2}{*}{ Asians } & Skibola, 2010 & 48 & 6 & 0 & 212 & 49 & 4 \\
\hline & & Hosgood, 2013 & 115 & 13 & 2 & 3091 & 506 & 25 \\
\hline \multirow{6}{*}{ CLL/SLL } & \multirow{6}{*}{ Caucasians } & Wihlborg, 1999 & 29 & 19 & 1 & 37 & 14 & 0 \\
\hline & & Mainou-Fowler, 2000 & 50 & 23 & 3 & 28 & 11 & 1 \\
\hline & & Jevtovic-Stoimenov, 2008 & 24 & 29 & 2 & 19 & 14 & 1 \\
\hline & & Fernberg, 2010 & 373 & 171 & 24 & 1007 & 431 & 46 \\
\hline & & Skibola, 2010 & 605 & 193 & 25 & 3791 & 1394 & 141 \\
\hline & & Lech-Maranda, 2013 & 213 & 67 & 8 & 136 & 53 & 3 \\
\hline \multirow{2}{*}{ MCL } & \multirow{2}{*}{ Caucasians } & Fernberg, 2010 & 76 & 33 & 10 & 1007 & 431 & 46 \\
\hline & & Skibola, 2010 & 90 & 35 & 6 & 3791 & 1394 & 141 \\
\hline MALT & Caucasians & Hellming, 2005 & 93 & 39 & 6 & 360 & 160 & 13 \\
\hline \multirow{2}{*}{ PTCL } & Caucasians & Skibola, 2010 & 125 & 53 & 5 & 3791 & 1394 & 141 \\
\hline & Asians & Liu, 2013 & 72 & 7 & 0 & 260 & 40 & 0 \\
\hline \multirow{2}{*}{$\mathrm{NK} / \mathrm{TCL}$} & \multirow{2}{*}{ Asians } & Hosgood, 2013 & 89 & 14 & 0 & 3091 & 506 & 25 \\
\hline & & Liu, 2013 & 81 & 6 & 0 & 260 & 40 & 0 \\
\hline
\end{tabular}

Abbreviations: NHL, non-Hodgkin lymphomas; BCL, B-cell lymphomas; TCL, T-cell lymphomas; DLBCL, diffuse large B-cell lymphomas; FL, follicular lymphomas; CLL/SLL, chronic lymphocytic leukemias/small lymphocytic lymphomas; MCL, mantle cell lymphomas; MALT, mucosal-associated lymphomas; PTCL, peripheral T-cell lymphomas; NK/TCL, NK/T-cell lymphomas.

\subsubsection{TNF- $\alpha-308 \mathrm{G}>\mathrm{A}$ and $\mathrm{NHL}$}

Of the combined 10,619 patients with NHL and 12,977 controls, no risk association was observed in TNF-308G $>$ A polymorphism and NHL with significant heterogeneity between studies $(\mathrm{OR}=1.06$, 95\% CI: $\left.0.92-1.23, p=0.413 ; \mathrm{I}^{2}=75.0 \%, p_{\text {het }}<0.001\right)$. In subgroup analysis based on population, significant associations were detected in Caucasian and Asian populations, respectively. In Caucasians with 7893 cases and 8447 controls, participants with TNF-308A allele had an increased NHL risk $\left(\mathrm{OR}=1.22,95 \%\right.$ CI: $\left.1.06-1.40, p=0.007 ; \mathrm{I}^{2}=60.7 \%, p_{\text {het }}=0.002\right)$. However, in Asians with 2726 cases and 4530 controls, decreased risk was observed $(\mathrm{OR}=0.75,95 \%$ CI: $0.66-0.86, p<0.001$; 
$\left.\mathrm{I}^{2}=0.0 \%, p_{\text {het }}=0.670\right)$. Figure 1 shows the forest plot of the overall association between TNF- $\alpha-308 \mathrm{G}>$ A polymorphism and NHL risk in additive model (A vs. G) stratified by ethnicity.

To evaluate the influence of each study on the pooled ORs in two subgroups, we deleted single study at a time to recalculate the influence of individual study for the outcome of the meta-analysis. The pooled ORs were stable and in an effective interval with statistical significant though the fixed-effect in additive model estimating before or after any single study deleted in each group (data not shown). These indicated that the results of this meta-analysis were reliable and had not been overly influenced by any one of studies.

We performed Begg's funnel plot and Egger's test to evaluate the publication bias of all included studies. Figure 2 shows no evidence of obvious asymmetry in overall analysis for TNF- $\alpha-308 \mathrm{G}>\mathrm{A}$ polymorphism in additive model $\left(p_{\text {Begg's }}=0.529\right)$. Egger's test also suggested no significant publication bias existed in this meta-analysis (additive model, $p=0.780$ ).

Figure 1. Overall association between TNF- $\alpha-308 \mathrm{G}>\mathrm{A}$ polymorphism and NHL risk (additive model) in Caucasian and Asian populations. For each study, the estimate of odds ratio (OR) and its $95 \%$ confidence interval $(\mathrm{CI})$ is plotted with a box and a horizontal line. The symbol diamond indicates pooled OR and its 95\% CI.

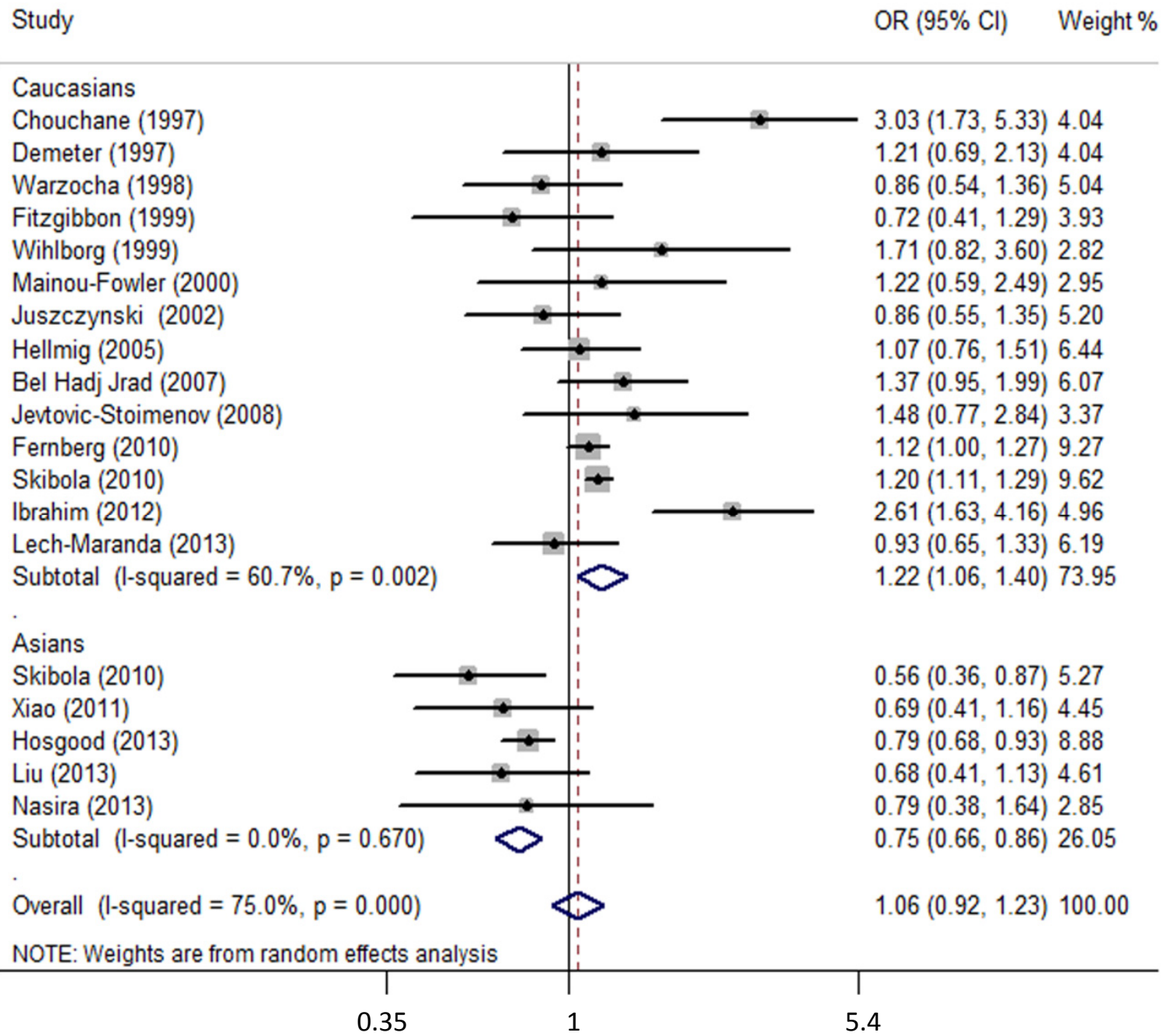


Figure 2. Begg's funnel plot for publication bias on the association between TNF- $\alpha-308 \mathrm{G}>\mathrm{A}$ polymorphism and NHL risk in additive model.

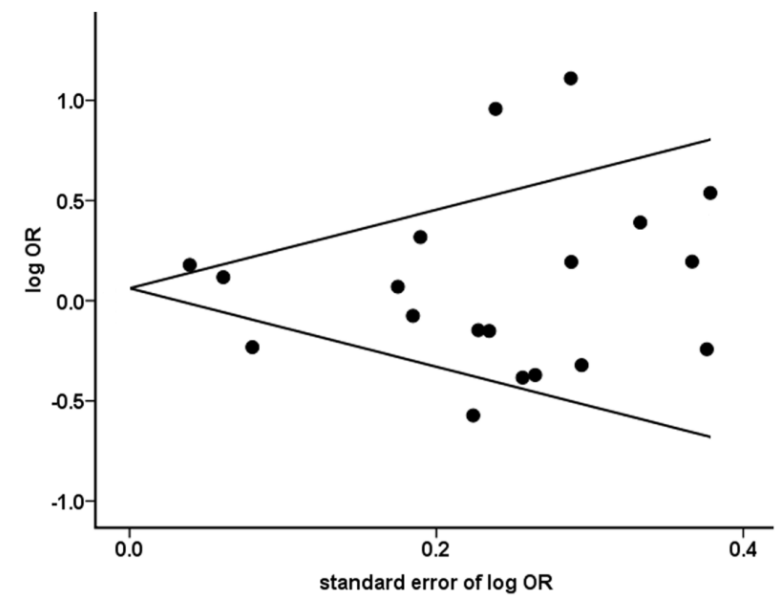

\subsection{2. $\mathrm{TNF}-\alpha-308 \mathrm{G}>\mathrm{A}$ and $\mathrm{B}-$ or $\mathrm{T}-\mathrm{CL}$}

Thirteen studies comprising a total of 20,064 participants (8092 cases with BCL and 11,972 controls) and 4 studies including 11,832 participants (1100 cases with TCL and 10,732 controls) were analyzed for an association between TNF- $\alpha-308 \mathrm{G}>\mathrm{A}$ polymorphism and BCL or TCL risk.

For BCL analysis, the pooled OR across all studies was not statistically significant (OR $=1.07,95 \%$ CI: $\left.0.91-1.26, p=0.411 ; \mathrm{I}^{2}=74.4 \%, p_{\text {het }}<0.001\right)$. Increased risk was found in Caucasians $(\mathrm{OR}=1.18$, 95\% CI: $\left.1.03-1.34, p=0.014 ; \mathrm{I}^{2}=44.6 \%, p_{\text {het }}=0.054\right)$, decreased risk was detected in Asians $\left(\mathrm{OR}=0.70,95 \%\right.$ CI: $\left.0.52-0.94, p=0.018 ; \mathrm{I}^{2}=41.9 \%, p_{\text {het }}=0.189\right)$. In TCL analysis, TNF-308A associated with a higher NHL risk in Caucasians $\left(\mathrm{OR}=1.20,95 \% \mathrm{CI}: 1.01-1.42, p=0.040 ; \mathrm{I}^{2}=0.0 \%, p_{\text {het }}=0.361\right)$.

\subsubsection{TNF- $\alpha-308 \mathrm{G}>\mathrm{A}$ and NHL Subtypes}

For DLBCL, the most common NHL subtype, there were 3353 cases and 10,817 controls included in the analysis. Consistent with the results for all NHL, the TNF- $\alpha-308 \mathrm{~A}$ allele was associated with an increased risk of DLBCL in Caucasians ( $\mathrm{OR}=1.21,95 \% \mathrm{CI}: 1.11-1.32, p<0.001 ; \mathrm{I}^{2}=0.0 \%$, $\left.p_{\text {het }}=0.491\right)$, but with a decreased risk in Asians (OR $=0.70,95 \%$ CI: $0.57-0.86, p=0.001 ; \mathrm{I}^{2}=0.0 \%$, $\left.p_{\text {het }}=0.908\right)$. The pooled OR was 0.97 (95\% CI: 0.75-1.26, $\left.p=0.840 ; \mathrm{I}^{2}=83.9 \%, p_{\text {het }}<0.001\right)$.

No associations were found in TNF- $\alpha-308 \mathrm{G}>\mathrm{A}$ polymorphism with FL, CLL/SLL, MCL, MALT, PTCL and NK/TCL in overall and each ethnic subgroup.

\subsection{Discussion}

In the pooled analysis of 18 articles, we found TNF- $\alpha-308 \mathrm{G}>\mathrm{A}$ polymorphism to be significantly associated with NHL risk in Caucasians and Asians. We provided evidence that subjects with TNF- $\alpha-308 \mathrm{~A}$ allele had an increased risk of NHL in Caucasians, and had a decreased risk in Asians. Similar results were confirmed in analyses of BCL and DLBCL. Further, the TNF- $\alpha-308$ A allele was positively associated with risks of TCL in Caucasians. Our study highlights the effect of TNF- $\alpha$ gene polymorphism on risks of NHL and its subtypes in different populations. These findings indicate a potential connection between constitutively higher TNF- $\alpha$ expression and pathogenesis of NHL. 
TNF- $\alpha$ is a transmembrane protein and mainly produced by macrophages and is expressed at low levels in a wide variety of cells. TNF- $\alpha$ mediates its effects through TNF- $\alpha$ receptor 1 and 2 (TNFR1 and TNFR2) by ligand passing and signal transduction. TNFR1 has a death domain that could interact with TNF- $\alpha$ receptor-associated death domain (TRADD), sequentially recruiting proteins to induce caspase-3 activation for apoptosis. TRADD could also bind TNF receptor-associated factor 2 (TRAF2) to recruits proteins activating IKK, GCK, and RIP, which finally leads to the NF- $\mathrm{BB}$, JNK, and MAPK pathway activation for anti-apoptosis and cell survival. Although TNFR2 lacks the death domain, it could also bind TRAF2 to active an anti-apoptosis pathway $[13,43]$. Aberrant NF- $\kappa \mathrm{B}$ activation is a hallmark of several lymphomas for promoting continuous lymphocyte proliferation, which is also directly linked to disease promotion $[44,45]$. When cells are exposed to TNF- $\alpha, \mathrm{NF}-\kappa \mathrm{B}$ pathway activation leads to the expression of many genes to cause chronic inflammation, which stimulates tumor growth. Dysregulated TNF- $\alpha$ contributes directly to the transformed state in many cancers, especially those of BCL [46]. Collectively, TNF- $\alpha$ acting as an immunoregulatory cytokine builds a bridge between inflammation and cancer by activating many biological pathways including the nuclear factor- $\kappa \mathrm{B}$ $(\mathrm{NF}-\kappa \mathrm{B})$ pathway in promoting cell proliferation, survival, transformation, invasion and angiogenesis.

Previous studies suggest higher expression of TNF- $\alpha$ is associated with NHL risk at the time of diagnosis [14-17]. These studies do not contradict the results of TNF- $\alpha-308 \mathrm{~A}$ allele inducing higher constitutively TNF- $\alpha$ expression associated with decreased NHL risk in Asians. With a heterogeneous malignancy and population diversity, we believe the level of constitutively TNF- $\alpha$ expression must play a different vital role at the step of NHL initiation in Caucasians and Asians, although the reasons for this have not been understood. Once a tumor forms, it secretes TNF- $\alpha$ to promote its survival, proliferation and metastasis. A subtype of TCL failing to express TNF- $\alpha$ and frequently with the TNF- $\alpha$ gene promoter methylated [47] indicates that epigenetic changes might also influence NHL susceptibility together. Environmental, occupational exposure and pathogenic agent infection (such as Epstein-Barr virus and human T-cell leukemia virus-1) are the well-known risk factors for NHL [48,49]. Therefore, genetic, epigenetic, tumor microenvironment, environment and their interaction could together contribute to NHL progression. Few studies about this kind of interaction relative to NHL susceptibility have been published. Due to insufficient data, our meta-analysis did not combine the effects of these factors in an association analysis between genetic variation and NHL risk. Much more precise investigations should be performed to clarify the true association of these types of interactions with polymorphism and NHL.

TNF- $\alpha$ and LT- $\alpha$ gene lie in the major histocompatibility complex class III, telemetric to the class II and centrometric to class I gene. Therefore, TNF- $\alpha$ being in linkage disequilibrium (LD) with these genes may also be linked to another region, haplotype or extended, that can influence NHL development [50]. This meta-analysis only evaluated one SNP in the TNF- $\alpha$ gene, though it was not possible to analyze haplotypes with the present data. Further studies will be needed to pool data and analyze whether haplotypes comprising TNF- $\alpha-308 \mathrm{G}>\mathrm{A}$ and other SNPs are linked to NHL risk, and clarify their function concomitantly.

Because of relatively low incidence of NHL, sample sizes of some studies included in this analysis are very small. The major strength of this study is the larger pooled sample size involving a total of 10,619 patients with NHL and 12,977 healthy controls for association study, which would largely 
minimize the possibility of chance findings. In addition, patients in our study were all Caucasians or Asians, which would exclude the biased results due to population stratification.

In conclusion, we performed the first comprehensive meta-analysis involving 10,619 patients with NHL and 12,977 controls from 18 articles to evaluate the association between TNF- $\alpha-308 \mathrm{G}>\mathrm{A}$ polymorphism and NHL risk. Our study showed that TNF- $\alpha-308 \mathrm{G}>\mathrm{A}$ SNP in the promoter region of TNF- $\alpha$ gene is associated with NHL risk. In addition, TNF- $\alpha-308 \mathrm{~A}$ increases risks of NHL, BCL, TCL and DLBCL in the Caucasian population; however, interestingly, it reduces risks of NHL, BCL and DLBCL in the Asian population. This association might be mediated by constitutive changes of TNF- $\alpha$ expression in individuals carrying the $-308 \mathrm{~A}$ allele, to induce inflammatory responses or the alternative pathway which be involved in NHL initiation and progression. Our meta-analysis emphasizes that genetic variation plays a crucial role in cancer; theTNF- $\alpha-308 \mathrm{G}>\mathrm{A}$ polymorphism might play a role in a specific subtype of NHL and its importance varies in different populations. Further studies should focus on the function of how variants affect NHL in different populations and the elucidation of the pathway involved which may eventually lead to a better understanding of tumorigenesis and contribute to the prevention of NHL.

\section{Experimental Section}

\subsection{Publication Search}

We carried out a search in three electronic databases PubMed, Embase and Cochrane Library to find relevant publications up to November 2013, using key words related to the TNF- $\alpha$ gene polymorphism in combination with various NHL subtypes [51]. The search was limited to studies that had been conducted on human subjects and without language restriction. Reference lists of the retrieved articles, reviews and editorials were also screened to find all additional eligible studies.

\subsection{Inclusion Criteria}

Selection of studies had to meet the following criteria: (1) case-control studies, family or sibling pairs studies were excluded; (2) published in English; (3) subjects were limited to adult and without autoimmune diseases, studies with children were also excluded; (4) DNA was extracted from peripheral blood leukocytes; (5) study described the association between TNF- $\alpha$-308 polymorphism and NHL risk; (6) sufficient data for estimating odds ratio (OR) and its corresponding 95\% confidence interval (95\% CI); (7) control group fulfilled HWE. When the same subject group occurred in more than one study, only the complete study was chosen to be included in this meta-analysis.

\subsection{Data Extraction}

An initial screening of title and abstract was performed for the first step, followed by further screening based on full-text review. Information was independently extracted from all eligible publications by two investigators (K.Z. and J.D.), including the first author, publication year, ethnicity, sample size, genotyping method, the number of each genotype in cases and controls. For studies with subjects of different ethnic groups and had sufficient information, we extracted data separately for each ethnicity. Disagreements were resolved through discussion. 


\subsection{Statistical Analysis}

We assessed the association between TNF- $\alpha-308 \mathrm{G}>\mathrm{A}$ polymorphism and NHL risk by crude ORs and $95 \%$ CIs in an additive model. Heterogeneity among studies was examined with $\mathrm{I}^{2}$ statistics. In this meta-analysis, $\mathrm{I}^{2}>50 \%$ was defined as heterogeneity. Fixed-effect model (Mantel-Haenszel method) was used to evaluate inter-study heterogeneity. If heterogeneity existed, random-effect model (DerSimonian-Laird method) was used. $Z$ test was used to determine the pooled OR and 95\% CI. Analyses were also conducted on the subgroups of studies based on ethnicity. The potential influence of publication bias was assessed using Begg's funnel plot and Egger's linear regression test $[52,53]$. To evaluate the effect of one single study on overall risk of NHL, sensitivity analyses by excluding every study and recalculating ORs and 95\% CI were conducted [54]. HWE in controls of each study was examined by the Pearson's goodness-of-fit $\chi^{2}$ test. All statistical tests were carried out with SPSS 16.0 (SPSS Inc., Chicago, IL, USA) and Stata 12.0 (StataCorp, College Station, TX, USA). A 2-tailed $p<0.05$ was considered as statistical significance.

\section{Conclusions}

We performed the first comprehensive meta-analysis involving 10,619 patients with NHL and 12,977 controls from 18 articles to evaluate the association between TNF- $\alpha-308 \mathrm{G}>\mathrm{A}$ polymorphism and NHL risk. Our study showed that TNF- $\alpha-308 \mathrm{G}>\mathrm{A}$ SNP in the promoter region of TNF- $\alpha$ gene is associated with NHL risk. In addition, TNF- $\alpha-308 \mathrm{~A}$ increases risks of NHL, BCL, TCL and DLBCL in the Caucasian population; interestingly, this polymorhism reduces risks of NHL, BCL and DLBCL in the Asian population. This association might be mediated by constitutive changes of TNF- $\alpha$ expression in individuals carrying the $-308 \mathrm{~A}$ allele, to induce inflammatory responses or the alternative pathway which be involved in NHL initiation and progression. Our meta-analysis emphasizes that genetic variation plays a crucial role in cancer; the TNF- $\alpha-308 \mathrm{G}>\mathrm{A}$ polymorphism might play a role in a specific subtype of NHL and its importance may vary in different populations. Further studies should be focused on how variants affect NHL in different populations and the elucidation of the pathways involved which may eventually lead to a better understanding of tumorigenesis and contribute to the prevention of NHL.

\section{Acknowledgments}

This work was supported by National Natural Science Foundation of China (No. 81302052) and Natural Science Foundation of Beijing (No. 7142061).

\section{Author Contributions}

Conceived and designed the experiments: K.Z. Performed the experiments: K.Z. and J.D. Analyzed the data: K.Z., J.D. and Y.Z. Wrote the paper: K.Z. J.D. and Y.Z.

\section{Abbreviations}

TNF, tumor necrosis factor; NHL, non-Hodgkin lymphomas; BCL, B-cell lymphomas; TCL, T-cell lymphomas; DLBCL, diffuse large B-cell lymphomas; FL, follicular lymphomas; CLL/SLL, chronic 
lymphocytic leukemias/small lymphocytic lymphomas; MCL, mantel cell lymphomas; MALT, mucosal-associated lymphomas; PTCL, peripheral T-cell lymphomas; NK/TCL, natural killer/T-cell lymphomas; OR: odds ratio; 95\% CI: 95\% confidence interval.

\section{Conflicts of Interest}

The authors declare no conflict of interest.

\section{References}

1. Shankland, K.R.; Armitage, J.O.; Hancock, B.W. Non-Hodgkin lymphoma. Lancet 2012, 380, 848-857.

2. Evans, L.S.; Hancock, B.W. Non-Hodgkin lymphoma. Lancet 2003, 362, 139-146.

3. Alexander, D.D.; Mink, P.J.; Adami, H.O.; Chang, E.T.; Cole, P.; Mandel, J.S.; Trichopoulos, D. The non-Hodgkin lymphomas: A review of the epidemiologic literature. Int. J. Cancer 2007, 120 (Suppl. 12), 1-39.

4. Kumar, V.; Matsuo, K.; Takahashi, A.; Hosono, N.; Tsunoda, T.; Kamatani, N.; Kong, S.Y.; Nakagawa, H.; Cui, R.; Tanikawa, C.; et al. Common variants on 14q32 and 13q12 are associated with DLBCL susceptibility. J. Hum. Genet. 2011, 56, 436-439.

5. Skibola, C.F.; Conde, L.; Foo, J.N.; Riby, J.; Humphreys, K.; Sille, F.C.; Darabi, H.; Sanchez, S.; Hjalgrim, H.; Liu, J.; et al. A meta-analysis of genome-wide association studies of follicular lymphoma. BMC Genomics 2012, 13, 516.

6. Zhai, K.; Tian, X.; Wu, C.; Lu, N.; Chang, J.; Huang, L.; Zhang, T.; Zhou, Y.; Qiao, Y.; Yu, D.; et al. Cytokine BAFF gene variation is associated with survival of patients with T-cell lymphomas. Clin. Cancer Res. 2012, 18, 2250-2256.

7. Berndt, S.I.; Skibola, C.F.; Joseph, V.; Camp, N.J.; Nieters, A.; Wang, Z.; Cozen, W.; Monnereau, A.; Wang, S.S.; Kelly, R.S.; et al. Genome-wide association study identifies multiple risk loci for chronic lymphocytic leukemia. Nat. Genet. 2013, 45, 868-876.

8. Tan, D.E.; Foo, J.N.; Bei, J.X.; Chang, J.; Peng, R.; Zheng, X.; Wei, L.; Huang, Y.; Lim, W.Y.; $\mathrm{Li}$, J.; et al. Genome-wide association study of B cell non-Hodgkin lymphoma identifies 3q27 as a susceptibility locus in the Chinese population. Nat. Genet. 2013, 45, 804-807.

9. Vijai, J.; Kirchhoff, T.; Schrader, K.A.; Brown, J.; Dutra-Clarke, A.V.; Manschreck, C.; Hansen, N.; Rau-Murthy, R.; Sarrel, K.; Przybylo, J.; et al. Susceptibility loci associated with specific and shared subtypes of lymphoid malignancies. PLoS Genet. 2013, 9, e1003220.

10. Zhu, K.; Levine, R.S.; Gu, Y.; Brann, E.A.; Hall, I.; Caplan, L.S.; Baum, M.K. Non-Hodgkin's lymphoma and family history of malignant tumors in a case-control study (United States). Cancer Causes Control 1998, 9, 77-82.

11. Altieri, A.; Bermejo, J.L.; Hemminki, K. Familial risk for non-Hodgkin lymphoma and other lymphoproliferative malignancies by histopathologic subtype: The Swedish Family-Cancer Database. Blood 2005, 106, 668-672.

12. Wang, S.S.; Slager, S.L.; Brennan, P.; Holly, E.A.; de Sanjose, S.; Bernstein, L.; Boffetta, P.; Cerhan, J.R.; Maynadie, M.; Spinelli, J.J.; et al. Family history of hematopoietic malignancies and risk of non-Hodgkin lymphoma (NHL): A pooled analysis of 10,211 cases and 11,905 controls from the International Lymphoma Epidemiology Consortium (InterLymph). Blood 2007, 109, 3479-3488. 
13. Sethi, G.; Sung, B.; Aggarwal, B.B. TNF: A master switch for inflammation to cancer. Front. Biosci. 2008, 13, 5094-5107.

14. Macia, J.; Gomez, X.; Esquerda, A.; Perez, B.; Callao, V.; Marzo, C. Value of the determination of TNF-alpha in the plasma of patients with non-Hodgkins lymphoma. Leuk. Lymphoma 1996, 20, 481-486.

15. Adami, F.; Guarini, A.; Pini, M.; Siviero, F.; Sancetta, R.; Massaia, M.; Trentin, L.; Foa, R.; Semenzato, G. Serum levels of tumour necrosis factor-alpha in patients with B-cell chronic lymphocytic leukaemia. Eur. J. Cancer 1994, 30A, 1259-1263.

16. Warzocha, K.; Ribeiro, P.; Bienvenu, J.; Roy, P.; Charlot, C.; Rigal, D.; Coiffier, B.; Salles, G. Genetic polymorphisms in the tumor necrosis factor locus influence non-Hodgkin's lymphoma outcome. Blood 1998, 91, 3574-3581.

17. Halida, Y.; Guo, X.H.; Aliya, R. Expression of plasma TNF-alpha and TNF-beta in different subtypes lymphoma and its significance. Zhonghua Xue Ye Xue Za Zhi 2011, 32, 695-697. (In Chinese)

18. Wilson, A.G.; di Giovine, F.S.; Duff, G.W. Genetics of tumour necrosis factor-alpha in autoimmune, infectious, and neoplastic diseases. J. Inflamm. 1995, 45, 1-12.

19. Neben, K.; Mytilineos, J.; Moehler, T.M.; Preiss, A.; Kraemer, A.; Ho, A.D.; Opelz, G.; Goldschmidt, H. Polymorphisms of the tumor necrosis factor-alpha gene promoter predict for outcome after thalidomide therapy in relapsed and refractory multiple myeloma. Blood 2002, 100, 2263-2265.

20. Ho, S.Y.; Wang, Y.J.; Chen, H.L.; Chen, C.H.; Chang, C.J.; Wang, P.J.; Chen, H.H.; Guo, H.R. Increased risk of developing hepatocellular carcinoma associated with carriage of the TNF2 allele of the -308 tumor necrosis factor-alpha promoter gene. Cancer Causes Control 2004, 15, 657-663.

21. Kroeger, K.M.; Carville, K.S.; Abraham, L.J. The -308 tumor necrosis factor-alpha promoter polymorphism effects transcription. Mol. Immunol. 1997, 34, 391-399.

22. Wilson, A.G.; Symons, J.A.; McDowell, T.L.; McDevitt, H.O.; Duff, G.W. Effects of a polymorphism in the human tumor necrosis factor alpha promoter on transcriptional activation. Proc. Natl. Acad. Sci. USA 1997, 94, 3195-3199.

23. Pikarsky, E.; Porat, R.M.; Stein, I.; Abramovitch, R.; Amit, S.; Kasem, S.; Gutkovich-Pyest, E.; Urieli-Shoval, S.; Galun, E.; Ben-Neriah, Y. NF- $\kappa$ B functions as a tumour promoter in inflammation-associated cancer. Nature 2004, 431, 461-466.

24. Batten, M.; Fletcher, C.; Ng, L.G.; Groom, J.; Wheway, J.; Laabi, Y.; Xin, X.; Schneider, P.; Tschopp, J.; Mackay, C.R.; et al. TNF deficiency fails to protect BAFF transgenic mice against autoimmunity and reveals a predisposition to B cell lymphoma. J. Immunol. 2004, 172, 812-822.

25. Skibola, C.F.; Bracci, P.M.; Nieters, A.; Brooks-Wilson, A.; de Sanjose, S.; Hughes, A.M.; Cerhan, J.R.; Skibola, D.R.; Purdue, M.; Kane, E.; et al. Tumor necrosis factor (TNF) and lymphotoxin-alpha (LTA) polymorphisms and risk of non-Hodgkin lymphoma in the InterLymph Consortium. Am. J. Epidemiol. 2010, 171, 267-276.

26. Rothman, N.; Skibola, C.F.; Wang, S.S.; Morgan, G.; Lan, Q.; Smith, M.T.; Spinelli, J.J.; Willett, E.; de Sanjose, S.; Cocco, P.; et al. Genetic variation in TNF and IL10 and risk of non-Hodgkin lymphoma: A report from the InterLymph Consortium. Lancet Oncol. 2006, 7, 27-38. 
27. Chouchane, L.; Ahmed, S.B.; Baccouche, S.; Remadi, S. Polymorphism in the tumor necrosis factor-alpha promotor region and in the heat shock protein 70 genes associated with malignant tumors. Cancer 1997, 80, 1489-1496.

28. Demeter, J.; Porzsolt, F.; Ramisch, S.; Schmidt, D.; Schmid, M.; Messer, G. Polymorphism of the tumour necrosis factor- $\alpha$ and lymphotoxin- $\alpha$ genes in chronic lymphocytic leukaemia. Br. J. Haematol. 1997, 97, 107-112.

29. Fitzgibbon, J.; Grenzelias, D.; Matthews, J.; Lister, T.A.; Gupta, R.K. Tumour necrosis factor polymorphisms and susceptibility to follicular lymphoma. Br. J. Haematol. 1999, 107, 388-391.

30. Wihlborg, C.; Sjoberg, J.; Intaglietta, M.; Axdorph, U.; Pisa, E.K.; Pisa, P. Tumour necrosis factor-alpha cytokine promoter gene polymorphism in Hodgkin's disease and chronic lymphocytic leukaemia. Br. J. Haematol. 1999, 104, 346-349.

31. Mainou-Fowler, T.; Dickinson, A.M.; Taylor, P.R.; Mounter, P.; Jack, F.; Proctor, S.J.; Nordon, J.; Middleton, P.G. Tumour necrosis factor gene polymorphisms in lymphoproliferative disease. Leuk. Lymphoma 2000, 38, 547-552.

32. Juszczynski, P.; Kalinka, E.; Bienvenu, J.; Woszczek, G.; Borowiec, M.; Robak, T.; Kowalski, M.; Lech-Maranda, E.; Baseggio, L.; Coiffier, B.; et al. Human leukocyte antigens class II and tumor necrosis factor genetic polymorphisms are independent predictors of non-Hodgkin lymphoma outcome. Blood 2002, 100, 3037-3040.

33. Hellmig, S.; Fischbach, W.; Goebeler-Kolve, M.E.; Folsch, U.R.; Hampe, J.; Schreiber, S. A functional promotor polymorphism of TNF- $\alpha$ is associated with primary gastric B-Cell lymphoma. Am. J. Gastroenterol. 2005, 100, 2644-2649.

34. Bel Hadj Jrad, B.; Chatti, A.; Laatiri, A.; Ahmed, S.B.; Romdhane, A.; Ajimi, S.; Chouchane, L. Tumor necrosis factor promoter gene polymorphism associated with increased susceptibility to non-Hodgkin's lymphomas. Eur. J. Haematol. 2007, 78, 117-122.

35. Jevtovic-Stoimenov, T.; Kocic, G.; Pavlovic, D.; Macukanovic-Golubovic, L.; Marjanovic, G.; Djordjevic, V.; Tosic, N.; Pavlovic, S. Polymorphisms of tumor-necrosis factor- $\alpha-308$ and lymphotoxin- $\alpha+250$ : Possible modulation of susceptibility to apoptosis in chronic lymphocytic leukemia and non-Hodgkin lymphoma mononuclear cells. Leuk. Lymphoma 2008, 49, 2163-2169.

36. Fernberg, P.; Chang, E.T.; Duvefelt, K.; Hjalgrim, H.; Eloranta, S.; Sorensen, K.M.; Porwit, A.; Humphreys, K.; Melbye, M.; Ekstrom Smedby, K. Genetic variation in chromosomal translocation breakpoint and immune function genes and risk of non-Hodgkin lymphoma. Cancer Causes Control 2010, 21, 759-769.

37. Ibrahim, A.; Abdel Rahman, H.; Khorshied, M.; Sami, R.; Nasr, N.; Khorshid, O. Tumor necrosis factor $\alpha-308$ and Lymphotoxin $\alpha+252$ genetic polymorphisms and the susceptibility to non-Hodgkin lymphoma in Egypt. Leuk. Res. 2012, 36, 694-698.

38. Lech-Maranda, E.; Mlynarski, W.; Grzybowska-Izydorczyk, O.; Borowiec, M.; Pastorczak, A.; Cebula-Obrzut, B.; Klimkiewicz-Wojciechowska, G.; Wcislo, M.; Majewski, M.; Kotkowska, A.; et al. Polymorphisms of TNF and IL-10 genes and clinical outcome of patients with chronic lymphocytic leukemia. Genes Chromosom. Cancer 2013, 52, 287-296.

39. Xiao, H.; Zhang, K. Genetic polymorphisms of tumor necrosis factor- $\alpha$ and lymphotoxin- $\alpha$ in Chinese patients with non-Hodgkin lymphoma. Ann. Hematol. 2011, 90, 725-727. 
40. Hosgood, H.D., 3rd; Au, W.Y.; Kim, H.N.; Liu, J.; Hu, W.; Tse, J.; Song, B.; Wong, K.F.; Lee, J.J.; Chanock, S.J.; et al. IL10 and TNF variants and risk of non-Hodgkin lymphoma among three Asian populations. Int. J. Hematol. 2013, 97, 793-799.

41. Liu, J.; Song, B.; Wang, T.; Liu, Y.; Hao, J.; Yu, J. Genetic variations in CTLA-4, TNF- $\alpha$, and LTA and susceptibility to T-cell lymphoma in a Chinese population. Cancer Epidemiol. 2013, 37, 930-934.

42. Nasiri, H.; Farajnia, S.; Rezamand, A.; Movassaghpour, A.A.; Esmaeili, H.A.; Monfaredan, A.; Mobarra, N.; Rahimifar, N.; Sahebi, L.; Farshdousti Hagh, M. Genetic variations of tumor necrosis factor- $\alpha-308$ and lymphtoxin- $\alpha+252$ in non-hodgkin lymphoma and acute lymphoblastic leukemia patients. Iran. J. Basic Med. Sci. 2013, 16, 990-995.

43. Chu, W.M. Tumor necrosis factor. Cancer Lett. 2013, 328, 222-225.

44. Jost, P.J.; Ruland, J. Aberrant NF-kB signaling in lymphoma: Mechanisms, consequences, and therapeutic implications. Blood 2007, 109, 2700-2707.

45. Shih, V.F.; Tsui, R.; Caldwell, A.; Hoffmann, A. A single NF $\kappa B$ system for both canonical and non-canonical signaling. Cell Res. 2011, 21, 86-102.

46. Younes, A.; Aggarwall, B.B. Clinical implications of the tumor necrosis factor family in benign and malignant hematologic disorders. Cancer 2003, 98, 458-467.

47. Zhang, Q.; Wang, H.Y.; Bhutani, G.; Liu, X.; Paessler, M.; Tobias, J.W.; Baldwin, D.; Swaminathan, K.; Milone, M.C.; Wasik, M.A. Lack of TNFalpha expression protects anaplastic lymphoma kinase-positive T-cell lymphoma (ALK + TCL) cells from apoptosis. Proc. Natl. Acad. Sci. USA 2009, 106, 15843-15848.

48. Brown, T.; Rushton, L. Occupational cancer in Britain. Haematopoietic malignancies: Leukaemia, multiple myeloma, non-Hodgkins lymphoma. Br. J. Cancer 2012, 107 (Suppl. 1), S41-S48.

49. Zhao, X.F.; Reitz, M.; Chen, Q.C.; Stass, S. Pathogenesis of early leukemia and lymphoma. Cancer Biomark. 2010, 9, 341-374.

50. Carroll, M.C.; Katzman, P.; Alicot, E.M.; Koller, B.H.; Geraghty, D.E.; Orr, H.T.; Strominger, J.L.; Spies, T. Linkage map of the human major histocompatibility complex including the tumor necrosis factor genes. Proc. Natl. Acad. Sci. USA 1987, 84, 8535-8539.

51. Harris, N.L.; Jaffe, E.S.; Diebold, J.; Flandrin, G.; Muller-Hermelink, H.K.; Vardiman, J. Lymphoma classification - from controversy to consensus: The R.E.A.L. and WHO Classification of lymphoid neoplasms. Ann. Oncol. 2000, 11 (Suppl. 1), 3-10.

52. Begg, C.B.; Mazumdar, M. Operating characteristics of a rank correlation test for publication bias. Biometrics 1994, 50, 1088-1101.

53. Egger, M.; Davey Smith, G.; Schneider, M.; Minder, C. Bias in meta-analysis detected by a simple, graphical test. BMJ 1997, 315, 629-634.

54. Lau, J.; Antman, E.M.; Jimenez-Silva, J.; Kupelnick, B.; Mosteller, F.; Chalmers, T.C. Cumulative meta-analysis of therapeutic trials for myocardial infarction. N. Engl. J. Med. 1992, $327,248-254$.

(C) 2014 by the authors; licensee MDPI, Basel, Switzerland. This article is an open access article distributed under the terms and conditions of the Creative Commons Attribution license (http://creativecommons.org/licenses/by/3.0/). 